\title{
Estratégias didáticas para o ensino da língua inglesa na educação básica
}

\author{
Meirilene Alves Fernandes \\ Mestre em Educação pela Universidade La Salle. \\ E-mail: meirileneunilasalle@gmail.com
}

Vera Lucia Felicetti

Coordenadora e professora no curso de Pós-Graduação em Educação da Universidade La Salle e professora no curso de Matemática.

E-mail:vera.felicetti@unilasalle.edu.br

Antonio Filipe Maciel Szezecinski

Doutorando no Programa de Pós-graduação em Educação da Universidade La Salle.

E-mail: antonio.szezecinski@gmail.com

Resumo: O presente artigo investigou diferentes estratégias didáticas baseadas nas quatro habilidades - ouvir, falar, ler e escrever -, que podem contribuir para a melhoria do processo de ensino e aprendizagem da língua inglesa no Ensino Fundamental. A pesquisa caracterizou-se por um estudo de caso, de caráter exploratório descritivo e abordagem qualitativa. Após a realização do pré-teste, estratégias didáticas foram desenvolvidas na narração da história de Snow White and the seven dwarfs. Após o desenvolvimento das estratégias aplicou-se o pós-teste. $A$ análise realizada no pré-teste, pós-teste e no corpus constituído pelos relatórios realizados em cada aula evidenciaram que diferentes estratégias didáticas usadas no ensino do inglês podem contribuir para a melhoria não somente do processo de aprendizagem dos alunos, mas também do processo de ensino.

Palavras-chave: ensino; aprendizagem; estratégias didáticas; língua inglesa; quatro habilidades.
Abstract: This article investigated different didactic strategies, based on the four skills - listening, speaking, reading and writing -, that can contribute to the improvement of the process of teaching and learning the English language in Elementary School. The research is characterized as a descriptive, exploratory case study with a qualitative approach. After administering a pre-test, didactic strategies were developed in the storytelling of the fairy tale Snow White and the seven dwarfs. After the strategies were developed, a post-test was administered. The analysis performed in the pre-test, post-test and in the corpus, made up of the reports produced in each class, evidenced that different didactic strategies used in the teaching of English can contribute to the improvement not only of the students' learning process, but also of the teaching process.

Keywords: Teaching, learning, didactic strategies, English language, four skills.
Recebido: 04/03/2019

Aprovado: 03/04/2019 
comunicação \& educação • Ano XXIV • número 1 • jan/jun 2019

1.PAIVA, Vera Lúcia Meneses de Oliveira e. Alíngua inglesa no Brasil e no mundo. In: PAIVA, Vera Lúcia Meneses de Oliveira (org.). Ensino de língua inglesa - reflexões e experiências. Campinas: Pontes, 1996. p. 9-29.

2. BRITISH COUNCIL. O ensino de inglês na educação pública brasileira. São Paulo: British Council, 2015. Disponível em: https://www.britishcouncil. org.br/sites/default/files/ estudo_oensinodo inglesnaeducacaopublicabrasileira.pdf. Acesso em: 9 jan. 2016.

3. BRASIL. Lei n 9.394 , de 20 de dezembro de 1996 Estabelece as diretrizes e bases da educação nacional. Diário Oficial da União, Brasília, DF, 23 dez. 1996. Seção 1, p. 27833.

4. BRASIL. Medida Provisória $n^{\circ} 746$ de 22 de setembro de 2016. Institui a política de fomento a implementação de escolas de Ensino Médio em tempo integral, altera a Lei $n^{\circ} 9.394$, de 20 de dezembro de 1996, que estabelece as diretrizes e bases da educação nacional, e a Lei $n^{\circ} 11.494$, de 20 de junho de 2007, que regulamenta o fundo de manutenção e desenvolvimento da educação básica e de valorização dos profissionais da educação, e dá outras providências. Diário Oficial da União Brasília DF, 17 fev. 2017. Seção 1, p. 1. Disponível em: http:// www. planalto.gov.br/ccivil_03/_ato2015-2018/2016/ $\mathrm{Mpv} / \mathrm{mpv} 746 . \mathrm{htm}$ ? Acesso em: 20 fev. 2016

5. BRITISH COUNCIL, 2015.

6. Ibidem.

\section{INTRODUÇÃO}

A língua inglesa tornou-se a língua global da contemporaneidade em virtude da utilização desse idioma em vários países. Cada vez mais as pessoas empregam a língua inglesa na tecnologia, no turismo, na ciência, no esporte, na aviação, nos negócios, entre outros. Quem aprende a língua inglesa, portanto, pode ampliar o acesso ao conhecimento por meio das informações obtidas de outros países.

Segundo Paiva ${ }^{1}$, estudar inglês tornou-se um fenômeno mundial, e o ensino e aprendizagem de inglês como língua estrangeira traz implicações sociais e políticas. Atualmente, os alunos têm contato com a língua inglesa mediante vários meios de comunicação, tais como emissoras de rádio, internet, televisão, agências internacionais de notícias, sistemas de comunicação, jogos e computadores. A língua inglesa também se faz presente na música, cinema, filmes, marcas de roupas e de carros etc.

O status da língua inglesa pode ser percebido pelo grande número de jornais, nomes de estabelecimentos e revistas que estão repletos de expressões em inglês ou que são publicados em língua inglesa, mesmo não sendo a língua oficial do país de publicação. Aprender a língua inglesa atualmente é tão importante quanto aprender uma profissão. Conforme estudo do British Council ${ }^{2}$, essa percepção é compartilhada por professores de inglês das escolas públicas do Brasil que acreditam que os principais motivos que justificam a necessidade de aprender inglês são: (1) tornar os alunos cidadãos do mundo; (2) instrumentalizar os alunos com uma língua muito usada no mercado de trabalho; e (3) ampliar a cultura geral dos alunos.

No Brasil, até setembro de 2016 o ensino de língua estrangeira era obrigatório a partir do $5^{\circ}$ ano, sem especificar qual idioma, deixando a escolha desse a cargo da comunidade escolar, conforme Lei 9.394, de 20 de dezembro de $1996^{3}$, que estabelece as diretrizes e bases da educação nacional (LDB). Dessa forma, a língua inglesa não está presente na totalidade das escolas brasileiras, realidade que poderá mudar em caso de aprovação da Medida Provisória 746 de 22 de setembro de 2016, que altera a LDB e institui a obrigatoriedade do ensino da língua inglesa a partir do $6^{-}$ano do Ensino Fundamental e no Ensino Médio ${ }^{4}$. O modelo de não obrigatoriedade pode ser uma das causas que contribuiu para o baixo nível de proficiência dos brasileiros, conforme percebe o British Council ${ }^{5}$.

Ainda assim, a orientação legal não estabelece regulamentos em relação à carga horária do ensino de inglês. Decisões desse âmbito partem dos órgãos responsáveis (secretarias de Educação) tanto dos estados quanto dos municípios. Dessa forma, pode-se afirmar que o ensino de inglês apresentou pouca regulamentação e não há padronização para sua realização. Conforme o British Council ${ }^{6}$, essa é uma das causas que impede uma avaliação em âmbito nacional do ensino de inglês nas escolas brasileiras, não existindo, portanto, indicadores que permitam uma melhor compreensão do cenário. Os professores participantes 
do estudo do British Council ${ }^{7}$ acreditam, no entanto, que melhorias são necessárias e apontam para as potencialidades que o ensino da língua possui, afinal "o inglês é uma disciplina que requer mais atividades lúdicas, coletivas e interativas para gerar engajamento dos alunos e envolvimento prático com a língua”.

Mesmo reconhecendo o potencial existente no ensino de língua inglesa, prevalece nas salas de aula a leitura, a escrita e a gramática em detrimento da expressão oral e entendimento de falas. Este fato pode ser verificado em levantamento realizado a partir do banco de dados da Biblioteca Digital Brasileira de Teses e Dissertações (BDTD), cujas pesquisas evidenciam a escrita e leitura em detrimento da escola e fala, bem como do observado durante a experiência profissional de uma das autoras em diversas escolas públicas da cidade de Anápolis, no estado de Goiás (GO), enquanto supervisora pedagógica da área de Língua Inglesa.

Assim, considerando a importância da língua inglesa na contemporaneidade e o potencial a ser explorado no seu ensino, tem-se a possibilidade de didáticas envolvendo as habilidades de ouvir, falar, ler e escrever apoiadas na narração da história de Snow White and the seven dwarfs. Assim, realizou-se um estudo de abordagem qualitativa, caracterizado como estudo de caso, de cunho descritivo e exploratório.

Utilizou-se como técnica de coleta de dados a aplicação de pré e pós-teste e as observações das aulas desenvolvidas através do registro no diário de campo da pesquisadora, além de aplicação de estratégias pedagógicas de ensino de inglês baseadas nas habilidades comunicativas, de forma que foi possível a verificação do desempenho dos alunos do $6^{\circ}$ ano do Ensino Fundamental. O pré-teste, pós-teste e os registros feitos no diário de campo, resultantes das observações, formaram o corpus, que, para autores como Moraes e Galiazzi ${ }^{8}$, corresponde ao material a ser analisado.

Para análise dos resultados do pré e pós-teste, esta pesquisa, em ambos, voltou-se à identificação de acertos, erros e respostas em branco, que foram descritos ao longo do texto. Quanto aos registros originados nas observações, estes foram descritos e interpretados com base na hermenêutica interpretativa, ou seja, na hermenêutica como metodologia de interpretação.

\section{ESTRATÉGIAS DIDÁTICAS: DEFININDO UM CONCEITO}

Sobre ensino, Santana ${ }^{9}$ admite que a priori o termo possui uma concepção mais conservadora, baseada na transmissão dos conhecimentos ou, ainda, relacionada ao condicionamento do aluno (instrução, adestramento), sendo vista como um movimento de mão única, no sentido professor-aluno e de cunho conteudista. $\mathrm{O}$ autor ressalta, no entanto, a possibilidade de entender o ensino como algo mais amplo, algo que foi possível a partir das correntes humanistas e cognitivo-construtivistas, que o enxergam como um processo de orientação, levando em consideração as necessidades do aluno e buscando

7. Ibidem, p. 15. 8. MORAES, Roque; GALIAZZI Maria do Carmo. Análise textual discursiva. ljuí: Editora Unijuí, 2007.

9. SANTANA, Givaldo Melo de. Metodologia do ensino-aprendizagem de línguas. São Cristóvão: Universidade Federal de Sergipe; Cesad, 2009 
atribuir significado ao conhecimento. O conceito ampliado do ensino proposto por Santana ${ }^{10}$ conecta-se ao que ele considera aprendizagem. Assim, o ensino pode ser percebido como um movimento contínuo que resulta na aprendizagem.

$\mathrm{O}$ autor também afirma que a aprendizagem põe em "relevo o aprendiz e o processo. Aqui não é importante o como ensina o professor, senão o como e para que aprende o aluno"11. A aprendizagem é, portanto, um fenômeno que se caracteriza por ir além da transmissão de conhecimentos e por ser um processo complexo, pois requer interação entre as partes ${ }^{12}$. Neste sentido, Piletti ${ }^{13}$ acredita que durante a aprendizagem os conteúdos devem possuir significado a ponto de serem relevantes para quem os aprende. A aprendizagem implica criticidade e dar sentido àquilo que se propõe como objeto de estudo. Santana ${ }^{14}$ exemplifica que, no caso de idiomas, a aprendizagem não se dá por meio do conhecimento da estrutura da língua, mas quando se confere significado a esse conhecimento dentro do contexto social do estudante, ou seja, quando a língua aprendida "altera a condução prática da vida" e quando "assimilada significativamente, em uso"15.

Durante o processo de aprendizagem da língua inglesa, cada aprendiz desenvolve as suas estratégias para melhor aprender este idioma. Alguns escutam músicas de seus cantores favoritos para aperfeiçoar a compreensão oral e aumentar o conhecimento de vocabulário, enquanto outros dão preferência a filmes e leitura de seus livros e histórias favoritos, e existem aqueles que criam grupos de conversação para praticar o inglês. Oxford define as estratégias de aprendizagem como: "ações realizadas pelos alunos para melhorar sua própria aprendizagem"16. As estratégias são importantes para a aprendizagem de línguas, porque elas atuam não somente na aprendizagem de um idioma, mas também no uso dessa língua. Utilizando estratégias adequadas de aprendizagem de línguas resultam maior proficiência, autoconfiança e, especialmente, desenvolvimento da competência comunicativa.

Em relação à estratégia para o ensino de inglês, Souza ${ }^{17}$ descreve que os professores observados em sua pesquisa preferiam a abordagem tradicional, ou seja, o ensino de regras gramaticais, leitura e escrita. O falar e o ouvir quase não eram trabalhados em sala de aula. Dessa forma, as práticas pedagógicas desenvolvidas pelos professores não ofereciam um ensino e aprendizagem voltados para a abordagem comunicativa. Para a autora, essa lacuna pode estar relacionada à formação do professor, por isso acredita que é necessário rever as práticas pedagógicas dos professores do curso de Letras para que contemplem as abordagens comunicativas no processo de ensino e aprendizagem da língua inglesa.

Krashen ${ }^{18}$ complementa neste sentido que um ambiente favorável à comunicação e amparado nas reais necessidades dos alunos leva a um ensino eficaz de línguas. Assim, o autor defende que não há uma estratégia única e definitiva, pois elas devem estimular a interação e estar ajustadas às necessidades de cada aluno ou grupo de alunos. Ao levar em consideração as particularidades do público e as interações culturais estabelecidas em sala de aula, o autor dá 
Estratégias didáticas para o ensino da língua inglesa na educação básica

- Meirilene Alves Fernandes, Vera Lucia Felicetti, Antonio Filipe Maciel Szezecinski

menos ênfase ao meio utilizado (livros, uso de tecnologia etc.) e confere um caráter pessoal e psicológico ao ensino de línguas, no lugar do caráter técnico-didático ainda predominante.

\section{O ENSINO DE INGLÊS COMO ABORDAGEM COMUNICATIVA}

De acordo com os Parâmetros Curriculares Nacionais, as abordagens de ensino estão alicerçadas em princípios de natureza variada, como: (1) sociointeracional da aprendizagem em sala de aula; (2) cognitivo, em relação ao modo como o conhecimento linguístico é constituído por meio do envolvimento na negociação do significado e também no que se refere aos pré-conhecimentos (língua materna e outros) do aluno; (3) efetivo, tendo em vista a experiência de vir a se constituir como ser discursivo em uma língua estrangeira; e (4) pedagógico, em relação ao fato de que o uso da linguagem é parte central do que o aluno tem de aprender. Esses princípios constituem a base do desenvolvimento de uma metodologia de ensino que envolve a questão de como ensinar determinados conteúdos pelo uso de diferentes procedimentos metodológicos ${ }^{19}$.

A abordagem comunicativa para o ensino de inglês foi iniciada na década de 1960 e 70 com o linguista inglês Henry G. Widdowson ${ }^{20}$ e o americano Robert Lado $^{21}$. Segundo os referidos autores, a proposta era apresentar uma abordagem comunicativa para o ensino e aprendizagem da língua inglesa que trabalhasse conjuntamente com as quatro habilidades (ouvir, falar, ler e escrever) centrada na comunicação e no processo de interação com os outros alunos e com o professor.

Na prática em sala de aula, o professor é orientado por uma série de princípios, pressupostos e mesmo crenças, que constituem o que se denomina abordagem de ensinar. Mesmo que o professor desconheça qual abordagem o norteia, esta, implicitamente, o conduz na sua prática. Existe a necessidade de que o professor conheça a sua abordagem para que possa explicar por que ensina como ensina e por que obtém os resultados que obtém ${ }^{22}$.

Larsen-Freeman ${ }^{23}$ enfatiza que o foco da abordagem comunicativa é o uso social da língua visando à comunicação e ao uso da linguagem, não importando a gramática ou a pronúncia correta, mas, sim, a execução de tarefas na língua-alvo, interagindo com o interlocutor, seja falando, escrevendo ou lendo, revisando e corrigindo até fazer a sua comunicação entendida e utilizando para isso as habilidades linguísticas de que a linguagem dispõe.

Em uma abordagem comunicativa, a língua é vista como um sistema que expressa significado e que tem por objetivo maior a interação entre os sujeitos ${ }^{24}$. Como bem entende Spicer-Escalante e DeJonge-Kannan ${ }^{25}$, o ensino e aprendizagem de língua inglesa em uma abordagem comunicativa se dá por meio de atividades que envolvem uma comunicação real. A introdução de vocabulários e da estrutura gramatical é feita não apenas de forma mecanicista, mas interativa e funcional, conforme o contexto e a necessidade que o aprendiz tem.
19. BRASIL. Secretaria de Educação Fundamental. Parâmetros Curriculares Nacionais: terceiro e quarto ciclos do Ensino Fundamental: Língua Estrangeira. Brasília, DF: Ministério da Educação; Secretaria Educação Fundamental, 1998.

20. WIDDOWSON, Henry $\mathrm{G}$. Aspects of language teaching. Oxford: Oxford University Press, 1990.

21. LADO, Robert. Introdução à linguística aplicada. 2. ed. Petrópolis: Vozes, 1972.

22. ALMEIDA FILHO, José Carlos P. Dimensões comunicativas no ensino de línguas estrangeiras. 8. ed. Campinas: Pontes, 2015.

23. LARSEN-FREEMAN, Diane. Teaching and principles in language teaching. 2. ed. Oxford: Oxford University Press, 1986.

24. ELLIS, R. Task-based language and teaching. Oxford: Oxford University Press, 2003.

25. SPICER-ESCALANTE, Maria Luisa; DEJONGE-KANNAN, Karin. Cultural mismatch in pedagogy workshops: training non-native teachers in communicative language Teaching. Theory and Practice in Language Studies, [S. I.], v. 4, n. 12, p. 2.437-2.444, 2014. 
Considerando que a música, o filme e a narração de histórias envolvem elementos importantes no processo de ensino, todas as estratégias são exploradas na abordagem comunicativa no ensino de inglês. Assim, entende-se que a abordagem comunicativa no ensino de inglês pressupõe o uso integrado de variadas estratégias e métodos, pois assume um caráter de desenvolvimento integral da comunicação. Entende-se, também, a partir do exposto, que, para tal, os interesses e a cultura dos alunos devem estar inseridos no processo de ensino e aprendizagem de inglês. Assim, além de facilitar o aprendizado, também se atribui significado e importância ao idioma.

Ao se considerar a abordagem comunicativa no ensino e aprendizagem de línguas, nota-se que essa proposta é a mais adequada para o desenvolvimento de atividades didáticas de língua inglesa. Dessa forma, intenciona-se a aplicação dessa abordagem no desenvolvimento da presente pesquisa, utilizando-se, portanto, de estratégias que envolvam as habilidades de ouvir, falar, ler e escrever.

Tais estratégias permeadas por atividades envolvendo filme e música, e apoiadas na narração de história, por exemplo, permitem a integração de mais de uma estratégia de ensino e aprendizagem de línguas. A narração de histórias, além de estimular a audição e, consequentemente, a compreensão auditiva do inglês, também facilita a leitura do mesmo conto em momento posterior. $\mathrm{Na}$ leitura, as técnicas de leitura conhecidas como scanning e skimming são passíveis de uso, afinal permitem um entendimento mais prático do texto. No primeiro caso, trata-se da compreensão mais imediata do texto, quando rapidamente se reconhece o tema e o sentido das suas ideias principais ${ }^{26}$. Já a técnica skimming diz respeito a uma leitura geral mais atenta, mas que não se apega à compreensão de cada palavra ${ }^{27}$. Ambas as técnicas podem ser usadas para a compreensão de contos, letras de músicas e legendas de vídeos, ou seja, dos mais variados formatos que um texto pode apresentar. Por isso, podem ser estimuladas estratégias que se referem à abordagem comunicativa de ensino e aprendizagem de inglês.

A busca de um entendimento pleno a respeito dos conceitos norteadores para as estratégias didáticas, bem como para a abordagem comunicativa do ensino de língua inglesa, permitiu formar uma base teórica para o desenvolvimento da metodologia da pesquisa. A maneira como a pesquisa é conduzida serve como uma forma de atender às principais dúvidas e objetivos de que ela própria está permeada. Afinal, a metodologia é bem mais que procedimentos; ela abrange entendimentos teóricos da abordagem, que são o conhecimento e

as experiências do pesquisador sobre determinado fato.

26. LINDSAY, Paul. Teaching English worldwide: a new practical guide to teaching English. Burlingame: Alta Book Center Publishers, 2000.

27. Ibidem.

\section{METODOLOGIA}

A presente pesquisa, portanto, utilizou-se da abordagem qualitativa, do tipo estudo de caso e de finalidade exploratória, uma vez que a pesquisadora aplicou durante quatro meses estratégias didáticas envolvendo a narração da história de Snow White and the seven dwarfs com os alunos do $6^{\circ}$ ano, como base ao processo de ensino e aprendizagem. As técnicas realizadas de coleta de dados 
se constituíram em atividades de pré-teste, pós-teste, observações registradas no diário de campo e ficha de desempenho individual elaborada para cada aluno, de modo a acompanhá-los no processo de aprendizagem em relação às quatro habilidades desenvolvidas.

A pesquisa foi realizada em uma escola estadual de Ensino Fundamental localizada na grande Porto Alegre, no Rio Grande do Sul (RS). A escolha por realizar a pesquisa em uma unidade pública é em virtude da atividade profissional dos autores estar relacionada com tal categoria administrativa de ensino.

A turma escolhida foi um $6^{-}$ano do período vespertino do Ensino Fundamental, durante um quadrimestre letivo. A faixa etária dos estudantes variava entre 11 e 13 anos. A turma era composta por 26 alunos, sendo 13 meninos e 13 meninas. Como já mencionado, a Base Nacional Comum Curricular $^{28}$ prevê que o ensino de inglês seja obrigatório a partir do $6^{\circ}$ ano, o que justifica a escolha do nível da turma. Foram planejadas e organizadas estratégias didáticas voltadas ao processo de ensino e aprendizagem da língua inglesa que contemplassem as quatro habilidades A partir dessas atividades, buscou-se estabelecer uma relação entre o antes e o depois do desenvolvimento das estratégias didáticas pautadas na narração da história de Snow White and the seven dwarfs. Assim, foi possível identificar se as estratégias escolhidas contribuíram para o desenvolvimento da aprendizagem dos alunos. Como apoio às observações, elaborou-se um diário de campo, documento no qual foram registrados os fatos relacionados à reação da turma perante as estratégias.

O pré-teste, pós-teste e os registros realizados no diário de campo, decorrentes das observações, formaram o corpus da análise. Os significados foram dados e descritos de acordo com o observado durante o desenvolvimento das atividades que envolviam as estratégias didáticas. Os alunos foram, ao longo da descrição, assim identificados: letra "A", de aluno, acompanhada de um número e da letra "F" ou "M", que indica feminino ou masculino, respectivamente. Desta forma, de $\mathrm{A} 1 \mathrm{~F}$ até A14F refere-se às alunas e de A15M até A24M, aos alunos. Assim, buscou-se preservar a identificação deles. Dois alunos não estavam presentes quando da realização do pré-teste, por isso o pós-teste por eles realizado não consta nesta análise. Foram ministradas dez aulas à turma participante das atividades. Os objetivos das aulas foram desde proporcionar ao aluno a compreensão da importância do aprendizado da língua inglesa até incentivá-los a dialogar em inglês com os colegas, apresentar-se a eles e fazer-lhes perguntas sobre informações pessoais.

\section{ANÁLISES DOS RESULTADOS OBTIDOS}

Os resultados do pré-teste mostram que os alunos que não responderam às questões ou erraram ou não tinham conhecimento da língua inglesa. Com a aplicação do pré-teste foi possível perceber que os alunos apresentaram mais dificuldade na habilidade da escrita e da fala, uma vez que, para responder a maioria das questões, os alunos necessitariam da habilidade da escrita, por exemplo.
28. BRASIL. Ministério da Educação. Secretaria da Educação Básica. Base Nacional Comum Curricular. Brasília, DF: MEC 2016. Disponível em: http:// basenacionalcomum.mec. gov.br/\#/site/inicio. Acesso em: 10 jan. 2017. 
Para que se possa ter uma ideia, a primeira questão do pré-teste serviu para avaliar as compreensões de escrita e leitura em língua inglesa pelos alunos. Nesta questão em específico, buscou-se identificar o conhecimento dos alunos em relação à identificação de um texto sobre os dados pessoais de um personagem. Era apresentado ao aluno uma pequena introdução deste personagem, contendo informações a respeito de seu nome completo, idade e do local de onde provinha. A totalidade dos alunos respondeu corretamente o item "a" da questão, e nos itens "b" e "c" foram registrados 17 acertos. Na atividade "b" três erraram e quatro deixaram em branco. Nesta questão, utilizou-se as estratégias de leitura e escrita para responder o sobrenome da Mônica.

Um outro exemplo de questão a ser ponderada também foi a que buscou verificar se os alunos conseguiriam usar a comunicação interpessoal ao perguntar e responder três questões em inglês. Tais questões levavam a respostas de "sim" ou não", buscando avaliar somente a compreensão tanto auditiva quanto comunicativa do aluno. Dos 24 alunos que realizaram a questão, apenas 16 conseguiram perguntar e responder corretamente, enquanto os demais a deixaram em branco.

Ao finalizar a análise do pré-teste, destaca-se a fala de Harmer ${ }^{29}$, uma vez que ele ressalta alguns motivos pelos quais os estudantes precisam ser estimulados a falar inglês na sala de aula. Segundo o autor, a prática de speaking dá aos alunos a oportunidade de se comunicar e de praticar a fala para a vida real e social. Assim, é importante que os professores despertem o interesse dos alunos quanto à importância da prática da oralidade, para que eles aprendam a pronúncia e desenvolvam a fala.

Variadas atividades foram aplicadas durante as sessões da Hora do Conto, estimulando as naturezas diversificadas das quatro habilidades a serem exploradas. Por exemplo, uma das atividades desenvolvidas logo no início das sessões da Hora do Conto havia sido na segunda aula do cronograma. Após ser explanado aos alunos sobre diferentes gêneros textuais, dos quais se discutiu o conto de fadas, foi introduzido o primeiro contato com a história a ser trabalhada. Logo após os exercícios que focavam na prática da leitura e na escuta em língua inglesa, foi desenvolvida uma atividade envolvendo os personagens principais do conto em forma de cruzadinha. O uso dessa estratégia teve por objetivo enriquecer o vocabulário do aluno e praticar a escrita e a escuta de forma lúdica.

Já para a execução de estratégias voltadas à leitura durante a Hora do Conto havia sido aplicado um quebra-cabeça, onde os alunos haviam recebido um pedaço de papel do tamanho de um cartão de visitas para cada aluno com textos sobre a história, enumerados de um a nove. Os papéis foram misturados e cada aluno pegou um dos cartões. Após a distribuição dos papéis, foi solicitado a eles que ficassem em silêncio, pois o texto iria ser lido em português

29. HARMER, Jeremy. The practice of English language teaching. 3. ed. Essex: Longman, 2001. e depois em inglês. Depois, o áudio da história, aplicado na aula anterior, foi novamente posto para que eles ouvissem e tentasse montar o quebra-cabeça do conto. Os alunos ouviam o texto na medida em que a professora ia pausando 
e perguntando qual era a enumeração do texto que correspondia àquele parágrafo. Assim, quem estivesse com o número colocava em ordem. $\mathrm{O}$ aluno podia sair do grupo dele e ir para outro grupo para montar o quebra-cabeça. $O$ grupo que conseguia terminar primeiro passava a ajudar outro grupo. Assim, os alunos ficaram envolvidos na estratégia e afirmaram que haviam conseguido compreender muitas palavras.

Para o desenvolvimento das habilidades comunicativas da língua inglesa, uma vez fornecido o insumo linguístico necessário ao decorrer das aulas, havia sido solicitado aos alunos que dramatizassem o conto. Para tanto, foram escolhidos 11 alunos para participar, enquanto os demais ficaram como plateia. Logo que foi entregue a história transcrita de Snow White and the seven dwarfs, cada um dos participantes teve que ler e interpretar de acordo com o tom de voz dos personagens. Foi passado o áudio do conto novamente para eles lembrarem como cada personagem falava. Essa atividade possibilitou perceber o quanto a narração de histórias mexe com o imaginário dos alunos, ativa a participação na aula, melhora as habilidades de comunicação, e amplia o vocabulário e a pronúncia das palavras. Assim, foi possível desenvolver as quatro habilidades.

Tanto a prática da conversação quanto da escrita foram habilidades estimuladas nas aulas que se seguiram, por meio da realização das diversas atividades relacionadas à narração da história. Além disso, a compreensão e a escuta da língua inglesa também foram aspectos abordados, compreendendo, assim, a proposta da pesquisa. Os dados supracitados mostraram que no pós-teste os participantes da pesquisa evoluíram nos acertos, mas a opção por não responder e deixar em branco ainda permaneceu em algumas questões. No entanto, não houve erros em nenhuma das questões, o que indica que a utilização de diferentes estratégias didáticas envolvendo as quatro habilidades pode contribuir para uma melhor aprendizagem.

Percebeu-se um progresso dos alunos. No pós-teste, eles se sobressaíram, acertando mais questões. Foi explicado aos alunos que eles iriam fazê-lo para verificar se houve avanço no conhecimento da língua inglesa após a realização das aulas previstas. Havia sido necessário esclarecer a eles que iriam receber o mesmo teste, acrescido de quatro questões relacionadas à narração de histórias. A respeito da primeira pergunta a ser respondida, todos os alunos conseguiram respondê-la corretamente. A mesma questão que avaliava os conhecimentos prévios dos alunos em torno de suas habilidades orais e da fala também foi aplicada. No pós-teste, foi possível averiguar que, entre os alunos avaliados, 22 obtiveram êxito nas respostas, enquanto apenas dois o deixaram em branco.

Verificou-se que usar diferentes estratégias como a narração de histórias pode ser uma forma produtiva para o processo de ensino e aprendizagem da língua inglesa. A verificação do desempenho dos alunos aconteceu durante o desenvolvimento de todas as atividades, não somente no pré ou pós-teste, que contemplaram atividades correspondentes às quatro habilidades já mencionadas. As anotações permitiram registrar a participação, interação e desempenho no listening, speaking, writing e listening. Os alunos, além de melhorarem o 
conhecimento acerca das quatro habilidades, também ampliaram o vocabulário e seu domínio. Isto se justifica devido às características das questões que compunham os testes, uma vez que elas contemplavam as quatro habilidades.

Quanto às habilidades desenvolvidas pelos participantes durante a pesquisa, de acordo com as observações realizadas, pode-se afirmar que listening foi a mais utilizada pelos alunos, ou seja, eles demonstraram mais facilidade na habilidade de ouvir seguida da habilidade reading ou de leitura. Os alunos, embora em menor quantidade, também apresentaram habilidade no speaking, isto é, na fala. Por fim, a habilidade menos desenvolvida foi a writing, que é a escrita. Tanto no pré-teste quanto no pós-teste, o desenvolvimento do falar e do escrever em inglês foram as habilidades em que eles mais tiveram dificuldade. É possível destacar, ainda, que é necessário trabalhar sempre as quatro habilidades, pois uma depende e complementa a outra. Elas mantêm uma interlocução constante e paulatina para a construção e desenvolvimento de uma língua, quer seja ela materna ou não. $\mathrm{O}$ uso das quatro habilidades contribui para aprimorar o processo de ensino e aprendizagem.

\section{CONSIDERAÇÕES FINAIS}

A aprendizagem de um novo idioma em um ambiente escolar apresenta desafios tanto para alunos quanto para professores. Para o aluno, a dificuldade pode residir no desconhecimento total da língua a ser aprendida, ou, ainda, por questões como timidez, dificuldades na fala ou na escuta, integração com os colegas e condições cognitivas. Já para os professores, o ensino de um idioma exige capacitação, disposição e flexibilidade, afinal as turmas tendem a ser heterogêneas, compostas por alunos que possuem suas particularidades e necessidades específicas de aprendizagem.

Além da já esperada diversidade dos alunos, a escola observada apresentou certa fragilidade, posto que, no mesmo semestre, a turma participante desta pesquisa teve a troca de dois professores de língua inglesa, sendo o segundo sem formação para tal.

A diversificação das estratégias também requer criatividade e disposição do docente no preparo das aulas. Como já descrito aqui, há uma série de atividades que se complementam entre si a partir de um assunto comum - nesse caso, o conto de Snow White and the seven dwarfs. Logo, foi necessária a elaboração de materiais para diversas atividades, as quais priorizaram a ludicidade e a facilidade de compreensão dos alunos.

A preparação do professor vem desde a escolha do conto, cujo enredo deve prover ao docente os conteúdos a serem trabalhados em aula. O conto escolhido para a pesquisa possui uma série de publicações e pode ser encontrado na forma impressa (livro) e gravada (vídeo), além de possuir trilha sonora específica e representação dos personagens em esculturas e brinquedos. Essa gama de versões possibilita ampliar o número de atividades e atingir uma boa exploração do conteúdo. A partir desse conto, é possível o ensino das cores, adjetivos, frutas, associações matemáticas e a ampliação do vocabulário. 
O professor necessita, portanto, estar preparado para extrair o máximo de conteúdo a partir do conto e, também, para elaborar atividades que venham a atender a necessidade de desenvolver as habilidades de ouvir, falar, ler e escrever um novo idioma.

Cabe destacar que, para a maioria dos alunos participantes da pesquisa, o contato com a língua inglesa deu-se somente nesse ano escolar, pois é quando está prevista a inserção obrigatória do idioma na trajetória escolar. Tal situação se refletiu em certa dificuldade de aprendizagem dos alunos. Nesse ponto, há uma crítica aos conteúdos obrigatórios que preveem o ensino da gramática, etapa que deveria ocorrer após certa apreensão do idioma no que diz respeito à compreensão (escuta) e fala (pronúncia e vocabulário). Porém, mesmo considerando que o conteúdo programático não seja o mais adequado para a aquisição de uma língua, as estratégias didáticas, quando trabalhadas em sua diversidade de modo a compreenderem as quatro habilidades, facilitam o ensino e a aprendizagem.

Dessa forma, as crianças apresentaram como principais dificuldades a pronúncia, por ser o primeiro contato da maioria, e a escrita, que geralmente é a habilidade que precisa de mais tempo para se desenvolver. Além disso, pontua-se que a frequência nas aulas também é fator importante no desenvolvimento do idioma - os alunos que apresentaram desempenho inferior aos demais foram aqueles que mais faltaram às aulas. Outra oportunidade que se abre ao se empregar as estratégias didáticas para ensino e aprendizagem do inglês é a possibilidade de trabalhar com temas interdisciplinares. Durante as aulas, foi possível trabalhar temas como geografia e matemática, de forma simples e lúdica.

Como já exposto, a narração de histórias pode ser bem explorada no ensino da língua inglesa, pois permite a diversificação de atividades que envolvem o contexto do conto, ou seja, permite o desenvolvimento de diferentes estratégias. Percebeu-se que a abordagem comunicativa e o uso de estratégias didáticas, no processo de ensino e aprendizagem da língua inglesa, apresentaram-se eficazes. Além de buscarem a melhoria nas habilidades de ouvir, falar, ler e escrever em língua inglesa, tais estratégias também colaboraram para a criação de um ambiente saudável na turma em relação ao convívio entre os alunos e a professora. Alguns empecilhos no que diz respeito ao convívio social foram identificados, como o medo de se expor e de ser motivo de riso. Tais situações, no entanto, foram contornadas, e as ocorrências diminuíram ao longo das aulas devido à interação proporcionada pelo desenvolvimento de diferentes estratégias didáticas.

$\mathrm{O}$ uso de estratégias didáticas para ensino e aprendizagem de inglês no ambiente escolar é uma forma de incentivar e estimular o aluno não somente no que diz respeito à apreensão de um novo idioma, mas, também, em relação à qualidade das relações sociais, ampliação do entendimento acerca do mundo e superação de dificuldades individuais, como a timidez. Nesta direção, o objetivo desta pesquisa - investigar se diferentes estratégias didáticas baseadas nas 
quatro habilidades (ouvir, falar, ler e escrever) podem contribuir para a melhoria do processo de ensino e aprendizagem da língua inglesa no $6^{\underline{0}}$ ano do Ensino Fundamental - foi respondido. E, por extensão, o problema da pesquisa também o foi. Além disso, este trabalho sinaliza novas possibilidades investigativas envolvendo diferentes estratégias didáticas no que concerne a outros componentes curriculares. Também se nota a necessidade de uma formação docente capaz de contemplar em seu fazer de sala de aula um conjunto de estratégias didáticas diferenciadas e capazes de contribuir para uma melhor aprendizagem.

\section{REFERÊNCIAS BIBLIOGRÁFICAS}

ALMEIDA FILHO, José Carlos P. Dimensões comunicativas no ensino de línguas estrangeiras. 8. ed. Campinas: Pontes, 2015.

BRASIL. Lei no 9.394, de 20 de dezembro de 1996. Estabelece as diretrizes e bases da educação nacional. Diário Oficial da União, Brasília, DF, 23 dez. 1996. Seção 1, p. 27833.

BRASIL. Medida Provisória n⿳0 746, de 22 de setembro de 2016. Institui a política de fomento à implementação de escolas de Ensino Médio em tempo integral, altera a Lei $\mathrm{n}^{\circ}$ 9.394, de 20 de dezembro de 1996, que estabelece as diretrizes e bases da educação nacional, e a Lei n⿳ำ 11.494, de 20 de junho de 2007, que regulamenta o fundo de manutenção e desenvolvimento da educação básica e de valorização dos profissionais da educação, e dá outras providências. Diário Oficial da União, Brasília, DF, 17 fev. 2017. Seção 1, p. 1. Disponível em: http://www.planalto.gov.br/ccivil_03/_ato2015-2018/2016/ Mpv/mpv746.htm?. Acesso em: 20 fev. 2018.

BRASIL. Secretaria de Educação Fundamental. Parâmetros Curriculares Nacionais: terceiro e quarto ciclos do Ensino Fundamental: Língua estrangeira. Brasília, DF: Ministério da Educação; Secretaria de Educação Fundamental, 1998.

BRITISH COUNCIL. O ensino de inglês na educação pública brasileira. São Paulo: British Council, 2015. Disponível em: https://www.britishcouncil.org. br/sites/default/files/estudo_oensinodo inglesnaeducacaopublicabrasileira. pdf. Acesso em: 9 jan. 2016.

ELLIS, Rod. Task-based language and teaching. Oxford: Oxford University Press, 2003.

KRASHEN, Stephen D. Principles and practice in second language acquisition. Oxford: Pergamon, 1987.

LADO, Robert. Introdução à linguística aplicada. 2. ed. Petrópolis: Vozes, 1972.

LARSEN-FREEMAN, Diane. Teaching and principles in language teaching. 2. ed. Oxford: Oxford University Press, 1986. 
LINDSAY, Paul. Teaching English worldwide: a new practical guide to teaching English. Burlingame: Alta Book Center Publishers, 2000.

MORAES, Roque; GALIAZZI, Maria do Carmo. Análise textual discursiva. Ijuí: Editora Unijuí, 2007.

OXFORD, Rebecca. Language learning strategies: what every teacher should know. Boston: Heinleand Heinle, 1990.

PAIVA, Vera Lúcia Meneses de Oliveira e. A língua inglesa no Brasil e no mundo. In: PAIVA, Vera Lúcia Meneses de Oliveira e (org.). Ensino de língua inglesa - reflexões e experiências. Campinas: Pontes, 1996. p. 9-29.

PILETTI, Claudino. Didática geral. 11. ed. São Paulo: Ática, 2007.

SANTANA, Givaldo Melo de. Metodologia do ensino-aprendizagem de línguas. São Cristóvão: Universidade Federal de Sergipe; Cesad, 2009.

SOUZA, Maria Gleide Macêdo. A prática pedagógica do professor de língua inglesa nas escolas públicas do Ensino Médio. 2005. 150 f. Dissertação (Mestrado em Educação) - Universidade Federal de Pernambuco, Recife, 2005.

SPICER-ESCALANTE, Maria Luisa; DEJONGE-KANNAN, Karin. Cultural mismatch in pedagogy workshops: training non-native teachers in communicative language Teaching. Theory and Practice in Language Studies, [S. l.], v. 4, n. 12, p. 2.437-2.444, 2014.

WIDDOWSON, Henry G. Aspects of language teaching. Oxford: Oxford University Press, 1990. 